\title{
Statistical analysis of ionospheric mid-latitude trough over the Northern Hemisphere derived from GPS total electron content data
}

\author{
Na Yang ${ }^{1,2,3}$, Huijun Le $e^{1,2^{*}}$ and Libo Liu' ${ }^{1,2}$
}

\begin{abstract}
This study statistically investigated the seasonal variation, magnetic local time (MLT) variation, geomagnetic activity dependence, and solar activity dependence of the mid-latitude trough using GPS total electron content (TEC) data from 2000 to 2014. The daily median Kp index was used to characterize the daily geomagnetic activity level. The results showed that the trough minimum position depended primarily on the geomagnetic activity, MLT, and the season. The trough depth depended primarily on the solar flux index (F107) and, to a lesser degree, on MLT. The trough depth increased as F107 increased and as the incidence angle of solar flux decreased. The trough equatorward half-width decreased as the geomagnetic activity increased. These variations in the GPS-TEC trough minimum position were compared with the variations in the TEC trough derived from the International Reference lonosphere (IRI)-2007 model. The GPS-TEC trough minimum position changed little with respect to F107, whereas the IRI-TEC trough minimum position showed a strong F107 dependence.
\end{abstract}

Keywords: Ionosphere, Mid-latitude trough, Statistic analysis, Geomagnetic activity variation, Solar activity variation

\section{Introduction}

The ionospheric mid-latitude trough is a depleted region of ionospheric plasma density in the nightside $\mathrm{F}$ region and lies just equatorward of the auroral equatorward boundary. Throughout the paper, trough will refer specifically to the mid-latitude trough. The trough generally consists of three parts: an equatorward wall, a trough minimum, and a poleward wall. Because the large electron density gradient on either side of the trough affects radio wave propagation, the precise position of the trough is very important for many practical activities, such as trans-ionospheric communication and navigation.

Since Muldrew (1965) discovered the trough with a topside sounder, the formation and maintenance

\footnotetext{
* Correspondence: lehj@mail.iggcas.ac.cn

'Key Laboratory of Earth and Planetary Physics, Institute of Geology and Geophysics, Chinese Academy of Sciences, Beijing, China

${ }^{2}$ Beijing National Observatory of Space Environment, Institute of Geology and Geophysics, Chinese Academy of Sciences, Beijing, China

Full list of author information is available at the end of the article
}

mechanisms of the trough have been studied extensively, but many properties of the trough remain incompletely understood. Several mechanisms have been proposed to explain the trough in the pre-midnight sector. The first mechanism is plasma stagnation and decay of ionization in darkness in a region where corotation and convection electric fields counteract each other (e.g., Knudsen 1974; Spiro et al. 1978; Collis and Häggström 1988; and Hedin et al. 2000). Another mechanism for the trough formation during periods of enhanced geomagnetic activity is related to large poleward electric field events, which are also called subauroral ion drifts (SAIDs). The enhanced electric field can cause depletions in electron concentration by enhancing the recombination rate (Schunk et al. 1976). In addition, westward plasma drift driven by the large poleward electric field also advects depleted plasma density to earlier magnetic times; as such, the highdensity plasma in earlier magnetic times can be displaced by the depleted plasma density. Rodger et al. (1992) pointed out that the trough is the "normal" ionosphere between the poleward wall and the equatorward

\section{勿 Springer}


wall. The poleward wall is formed by precipitation or plasma transported from elsewhere (Rodger et al. 1986), and the equatorward wall is formed by corotating plasma that continues to decay with time and replenishment from the plasmasphere, but the maintenance mechanism is absent in the vicinity of the trough. Evans et al. (1983) pointed out that the trough formed in the dusk-side region may be a fossil corotating into the nightside sector toward dawn. It is worthy to note that a specific mechanism alone cannot account for density depletion, because the F region plasma is long-lived and a particular mechanism may not be at work throughout the observation period (Nilsson et al. 2005).

The trough has been investigated using various data and methods such as data from satellites, tomography, total electron content (TEC), incoherent scatter radar (ISR), and models (Muldrew 1965; Nilsson et al. 2005; Pryse et al. 2006; Middleton et al. 2008; He et al. 2011; Lee et al. 2011; Ishida et al. 2014). Currently, due to the fast-growing number of ground-based GPS receivers, GPS-TEC measurements have been increasingly used for upper atmospheric research. Horvath and Essex (2003) used TEC measurements from three stations to investigate the features of the Southern Hemisphere trough. Wielgosz et al. (2004) showed that the structure of the ionosphere trough can be regularly identified from latitudinal GPS-TEC plots. In addition, Krankowski et al. (2008) and Zou et al. (2011) utilized GPS-TEC data to study the trough over Europe and Alaska, respectively. These studies demonstrated that GPS-TEC can be used to routinely identify the ionosphere trough.
Figure 1 illustrates the global distribution of observed TEC from 0000 to 0200 UT on 1 January 2001. The trough center under very quiet magnetic conditions is located near $60^{\circ}$ corrected geomagnetic coordinates (Mendillo and Chacko 1977). The lines of $60^{\circ}$ magnetic latitude are included in Fig. 1. It can be seen that the number of the ground-based GPS receiver stations around the $60^{\circ} \mathrm{N}$ magnetic latitude is larger than those around the $60^{\circ} \mathrm{S}$ magnetic latitude. In addition, there is a much better data distribution in the Northern Hemisphere than in the Southern Hemisphere. Therefore, the trough over the Northern Hemisphere was investigated in this study. The TEC data offer a good opportunity to construct a better global climatology of the trough. In this paper, we first analyzed the trough structure for geomagnetic activity variation during equinox and for solar activity variation in different seasons. Then, we analyzed the MLT variation of the trough structure in different seasons. For our final analysis, we focused on a comparison between IRI-2007 results and GPS-TEC measurements.

\section{Data analysis}

The GPS-TEC data used in this study were downloaded from MIT Haystack's Madrigal database mirror site at the Institute of Geology and Geophysics, Chinese Academy Sciences (http://madrigal.iggcas.ac.cn/madrigal/). There are more than 2000 GPS receivers distributed across the globe. MIT Haystack has automated the process of downloading and processing GPS data (Rideout and Coster 2006) to produce globally gridded TEC data with a

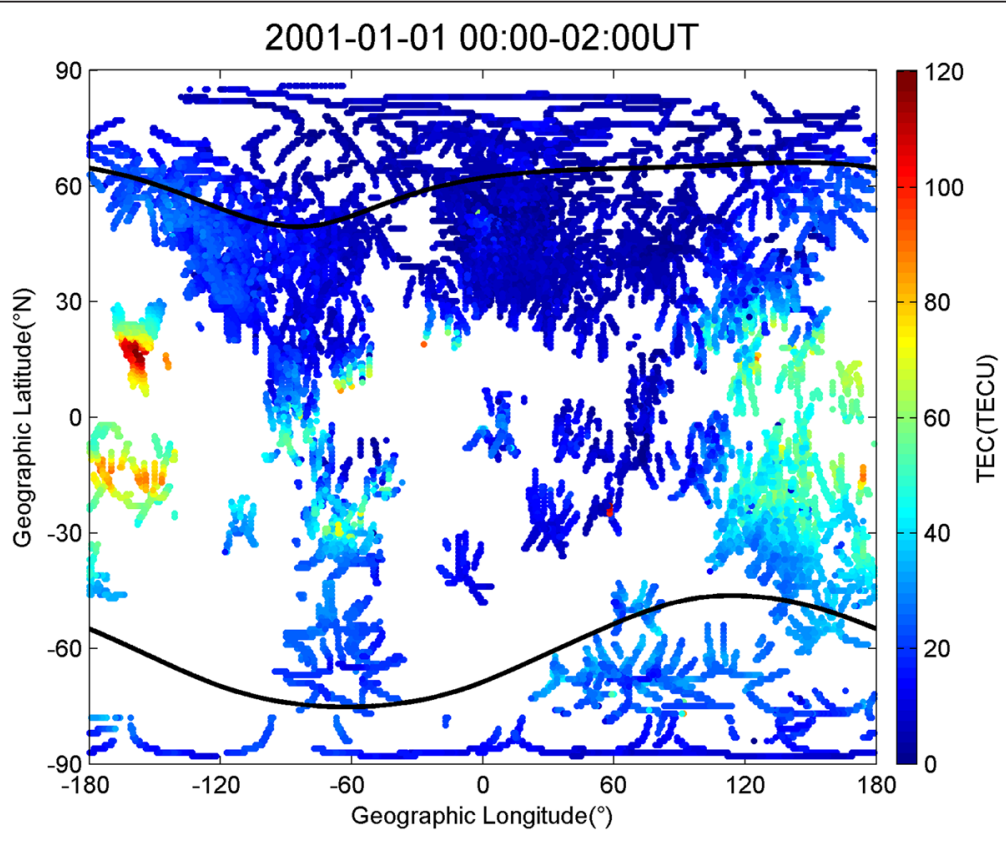

Fig. 1 Global observations of total electron content (TEC) during 0000-0200 UT 1 January 2001. The black lines are $60^{\circ} \mathrm{N}$ and $60^{\circ} \mathrm{S}$ magnetic latitude 
resolution of $5 \mathrm{~min}$. The geomagnetic activity index $\mathrm{Kp}$ and solar flux index F107 data were downloaded from the National Geophysical Data Center (ftp://ftp.ngdc.noaa. gov/STP/GEOMAGNETIC_DATA/INDICES/KP_AP/). In this study, we primarily investigated the trough structure averaged longitudinally over a day. As such, the daily median Kp index was used to characterize the daily geomagnetic activity level. In order to study the seasonal variation of the mid-latitude trough, the data were divided into three seasons: summer (May-July), equinox (FebruaryApril, August-October), and winter (November-January).

Because the trough is associated with geomagnetic activity, as reported by previous studies, we converted the GPS-TEC data in geographic coordinates to magnetic coordinates. In our work, the data were longitudinally averaged; therefore longitudinal or universal time variation was not expected in our analysis. In addition, data with a maximum relative error of $50 \%$ were used in the data processing procedures. To approximate the location of the trough minimum, the nighttime TEC data were used to construct latitudinal TEC profiles. Figure 2 shows an example of the nighttime latitudinal TEC profile from 10 January 2003. The latitudinal TEC profiles over the Northern Hemisphere and between $45^{\circ}$ and $70^{\circ} \mathrm{N}$ are presented in Fig. 2a, b, respectively. The daily trough minimum position $\left(T_{\mathrm{M}}\right)$ was identified from each latitudinal TEC profile between $45^{\circ}$ and $70^{\circ} \mathrm{N}$ (see Fig. 2b). The statistical results showed that $95 \%$ of the daily trough minimum positions were located in a magnetic latitude range of about $50^{\circ}-65^{\circ} \mathrm{N}$. In addition, taking into account the overall structure of the trough, the latitude range of $45-70^{\circ} \mathrm{N}$ was chosen to define the trough parameters. The trough minimum position $\left(T_{\mathrm{M}}\right)$ and the locations of the average TEC between $45^{\circ}$ and $70^{\circ} \mathrm{N}\left(T_{\mathrm{E}}\right.$ and $\left.T_{\mathrm{P}}\right)$ were identified from each plot (see Fig. 2). According to the analysis of Karpachev (2003), the point of inflection at the trough equatorial wall is often determined uncertainly, and the data points at the poleward maximum are very spread. In this study, the average TEC value of the data between $45^{\circ}$ and $70^{\circ} \mathrm{N}$ was defined as the background TEC. The trough depth was the difference between the background TEC and the TEC at the trough minimum. The latitudinal difference between the average TEC locations $\left(T_{\mathrm{E}}\right.$ and $\left.T_{\mathrm{P}}\right)$ was defined as the trough width. The equatorward and poleward half-widths were estimated from the latitudinal differences between the trough minimum and the respective average TEC locations $\left(T_{\mathrm{E}}\right.$ and $\left.T_{\mathrm{P}}\right)$.

The TEC maps were used to create latitudinal TEC profiles (between $45^{\circ}$ and $70^{\circ} \mathrm{N}$ ) with intervals of $2 \mathrm{~h}$ and $1^{\circ}$ steps in latitude. At first, the trough signature in the latitudinal TEC profile was recognized visually. Then, an automated procedure was used to estimate the trough parameters that formed the dataset used in this study. Although visual identification always involves some subjective judgment, the larger data sample was expected to smooth out such deficiencies.

\section{Results and discussion}

It is well known that the trough structure strongly depends on geomagnetic activity. Herein, we statistically examined the correlation between the Kp index and the trough minimum position. The data with F107 ranges from 100 to 115 solar flux unit (sfu; $1 \mathrm{sfu}=10^{-22} \cdot \mathrm{m}^{-2} \cdot \mathrm{Hz}^{-1}$ ) were used to study geomagnetic activity dependence. The total number of data points used in the study of geomagnetic activity was 374 . The data covered the near-midnight region (2300-0100 MLT). Figure 3 shows a scatter plot of the midnight trough minimum position as a function of the daily Kp index during equinox. The correlation coefficient and the linear regression equation by the least squares method are also shown in the figure. It is clear that a linear

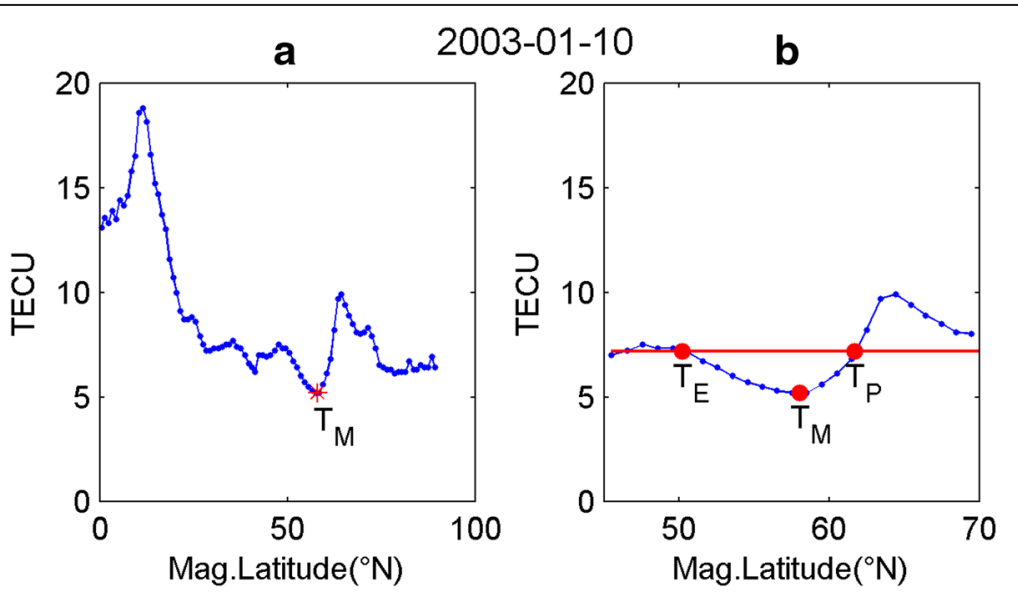

Fig. 2 a, b The nighttime TEC latitudinal profile on 10 January $2003(K p=2.5, F 107=178.7) . T_{M}$ corresponds to the trough minimum position. $T_{E}$ and $T_{P}$ are the average TEC locations on the equatorward and poleward sides of the trough minimum, respectively 


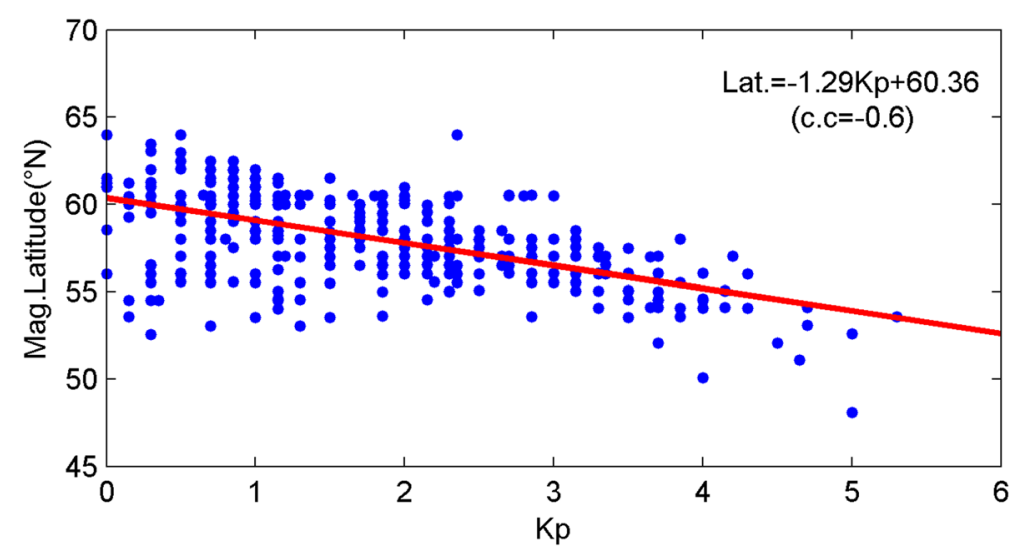

Fig. 3 The trough minimum position versus the daily Kp index during equinox. The data correspond to the near-midnight region (2300-0100 MLT) and median solar activity $(100 \leq$ F107 $\leq 115)$. The red solid line shows the linear fit of the data. The correlation coefficient (c.c.) and the linear regression equation are also shown in the figure

correlation is present between the trough minimum position and the Kp index, implying that the day-to-day variability of the trough structure is associated with daily geomagnetic activity. As shown, the trough minimum position moves to a lower latitude as geomagnetic activity increases. Krankowski et al. (2008) showed that the slope of the fitting line for the TEC trough position over Europe as a function of $3 \mathrm{~h} \_\mathrm{Kp}$ indices was about 1.0 to 1.6 in January 2005, whereas our results were about 1.8 to 2.0 for the winter season. Karpachev et al. (1996) concluded that the relationship between the trough minimum position and $\mathrm{Kp}$ is different at different longitudes. The discrepancy between the slopes is related to the longitudinal effect of the trough minimum position. In addition, the same order of magnitude of the slopes implies that the daily median $\mathrm{Kp}$ index is suitable for quantifying the level of geomagnetic activity. Krankowski et al. (2008) showed that the slope of the TEC trough is lower than that of the trough at height of about $550 \mathrm{~km}$, which may be due to the fact that the spatial structure of the trough occurrence depends on height.

Figure 4 shows variations in trough depth, background TEC, and the TEC value at the trough minimum with respect to the daily $\mathrm{Kp}$ index during equinox. It can be seen from Fig. 4c that the TEC values at the trough minimum were about 4-5 TECU, regardless of the Kp level. Despite the large scatter of the data in Fig. 4b, there is a trend for the background TEC to increase with increasing Kp. The variation in trough depth with respect to daily $\mathrm{Kp}$ index resembles the variation of the background TEC. Rodger et al. (1986) concluded that convection of plasma appears to be the most important process forming the poleward edge of the trough after magnetic midnight when geomagnetic activity is steady or decreasing. Additionally, local particle precipitation may be important when activity is increasing. As such, during periods of enhanced geomagnetic activity, the increase of TEC on the poleward wall in association with local energetic charged particles precipitation results in an increase of the background TEC. In addition, the background TEC is also associated with the TEC value of the equatorward wall, which depends on the positive and negative phases of a storm. Therefore, the correlation coefficient between background TEC and daily Kp is low. A more detailed study of this point would require additional information on the TEC values within the trough wall.

We also investigated the dependence of the trough latitudinal width and the trough half-widths on geomagnetic activity. Figure 5 shows the variation of the trough equatorward half-width, poleward half-width, and width versus daily $\mathrm{Kp}$ index during equinox. Figure $5 \mathrm{a}$, c shows that the trough equatorward half-width and the trough width decreased by about $0.57^{\circ}$ and $0.7^{\circ}$ per unit of Kp, respectively. The correlation coefficient between the poleward half-width and the daily $\mathrm{Kp}$ index was very low, which means that there is no linear correlation between them. In addition, the equatorward half-width was correlated with the trough minimum position; the correlation between the two was 0.55 . These correlations imply that the trough minimum position and the poleward wall are shifted equatorward more significantly than the equatorward wall as $\mathrm{Kp}$ increases. The results are consistent with the findings of Pryse et al. (2006).

In the next section, we examine the dependence of the trough structure on solar activity during three seasons under a low geomagnetic activity level $(1.5 \leq \mathrm{Kp} \leq 2.5)$. The total number of data points used for the summer, equinox, and winter seasons was 381, 732, and 300, respectively. The data covered the near-midnight region (2300-0100 MLT). Figure 6 shows the variation in 

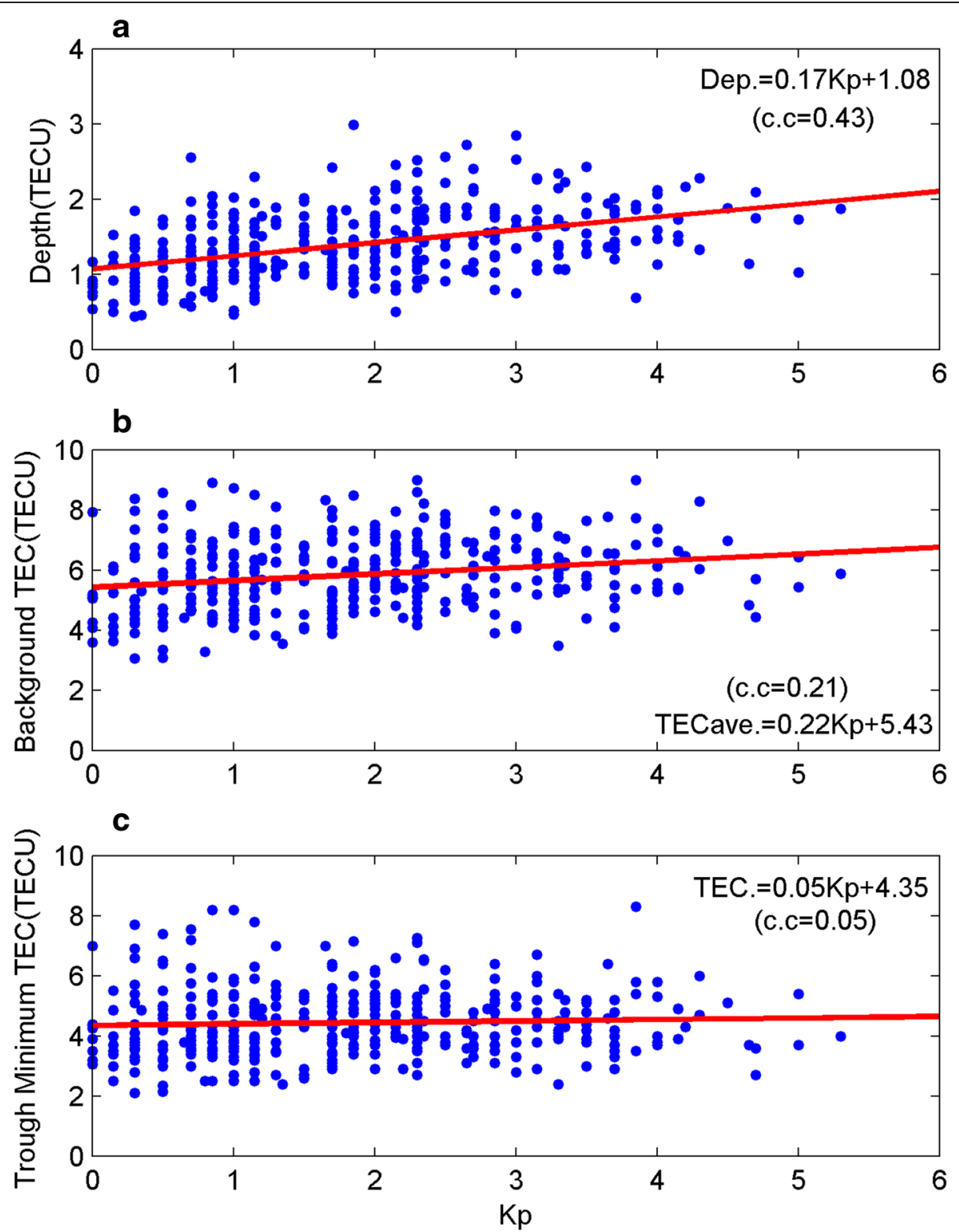

Fig. 4 The geomagnetic activity variations in the trough depth (upper panel (a)), background TEC (middle panel (b)), and TEC value at the trough minimum position (lower panel (c)) during equinox. The data correspond to the near-midnight region (2300-0100 MLT) and median solar activity (100 $\leq$ F107 $\leq 115)$. The red solid lines show the linear fit of the data. The correlation coefficients (c.c.) and the linear regression equations are also shown in the figure

trough minimum position with respect to the F107 index during the summer, equinox, and winter seasons. It is clear that the trough minimum position remained unchanged irrespective of the intensity of solar activity. As such, the variation in the trough minimum position is unaffected by solar activity.

In addition to location, trough depth is also of interest, as it may provide clues to the mechanism of trough formation. Figure 7 shows the solar activity variation of trough depth (upper panels), background TEC (middle panels), and TEC value at the trough minimum (lower panels) at a low geomagnetic activity level. The left, middle, and right columns show the results for the summer, equinox, and winter seasons, respectively. The red solid lines represent the piecewise fitting results. As seen in Fig. 7, the increase of TEC with respect to F107 is much steeper at low and moderate F107 values than at high values. The saturation effects in the ionospheric parameters have been reported by many earlier studies (e.g., Balan et al. 1996; Liu et al. 2003; Liu et al. 2006). In order to facilitate the analysis, the fitting lines are shown in Fig. 8. Figure 8 shows that the trough depth, 

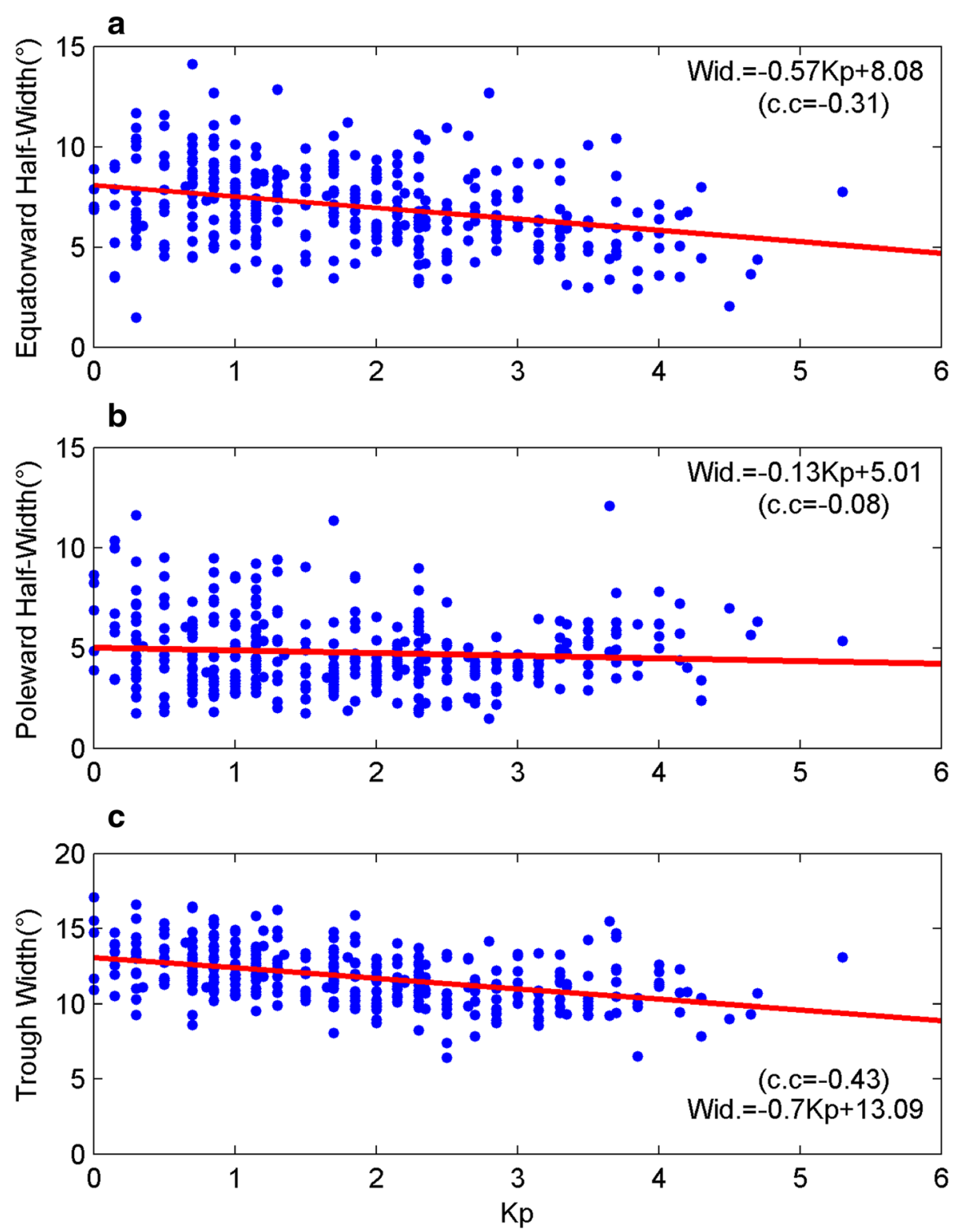

Fig. 5 The geomagnetic activity variations in the trough equatorward half-width (upper panel (a)), trough poleward half-width ((middle panel (b)), and trough width (lower panel (c)) during equinox. The data correspond to the near-midnight region (2300-0100 MLT) and median solar activity $(100 \leq$ F107 $\leq 115)$. The red solid lines show the linear fit of the data. The correlation coefficients (c.c.) and the linear regression equations are also shown in the figure

background TEC, and the TEC value at the trough minimum increased with increasing F107 for all seasons. In addition, the correlation between TEC value at the trough minimum and background TEC was about 0.98 . It is already known that the loss of electrons is proportional to the electron concentration. Therefore, the increase of background TEC caused by solar activity primarily leads to an increase of trough depth. Some simulations and observational evidence (e.g., Doe et al. 1995 and Nilsson et al. 2005) have indicated a relationship between the F region trough and downward field- aligned currents (FACs). The downward FAC can cause decreased ionospheric densities in the evening sector. Therefore, the region 2 (R2) FAC could possibly play a direct role in the formation of the midlatitude trough (Lyatsky and Mal'tsev 1981). Ohtani et al. (2014) showed that R2 current is more intense in high solar activity. Therefore, the intensification of the R2 current in high solar activity can also lead to an increase of the trough depth.

In the next section, we examine the diurnal variations of trough structure during three seasons. Median solar 

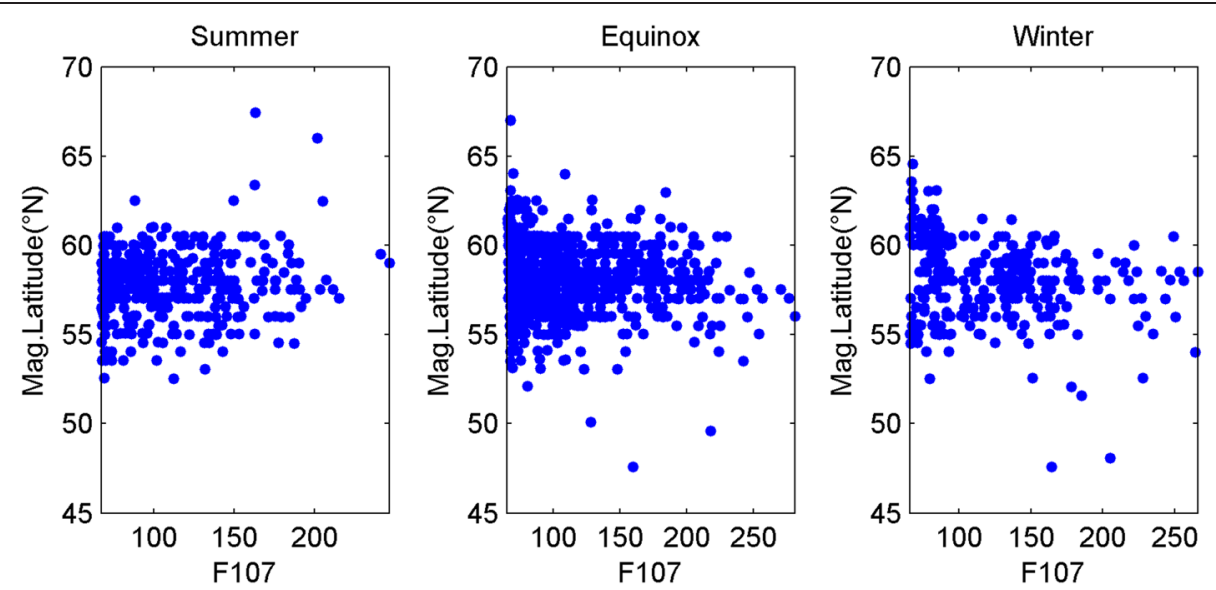

Fig. 6 The trough minimum position versus F107 under a low $(1.5 \leq \mathrm{Kp} \leq 2.5)$ geomagnetic activity condition. The left, middle, and right panels show the results for the summer, equinox, and winter seasons, respectively

activity $(90 \leq \mathrm{F} 107 \leq 150)$ and a low geomagnetic activity level $(0.3 \leq \mathrm{Kp} \leq 2)$ were selected to ensure the same conditions for each season $(\mathrm{F} \overline{0} 07=113, \overline{\mathrm{Kp}}=1.15)$. The total number of data points for the summer, equinox, and winter seasons was 186,142 , and 375 , respectively. Figure 9 illustrates the MLT variation in the trough minimum position during the summer, equinox, and winter seasons. As illustrated in Fig. 9, the results showed a significant MLT variation in the trough minimum position. The trough minimum position first moves progressively toward lower latitudes, with the lowest latitude around 0400 MLT; it then moves back toward higher latitudes. This result agrees with those found in many earlier studies (e.g., Karpachev et al. 1996; Krankowski et al. 2008; and Lee et al. 2011). It is noteworthy that the range of the trough latitude variation during the dusk-side to morning region (2100-0400 MLT) in summer was larger than the range in other seasons. The trough minimum position decreased with MLT in the pre-midnight to postmidnight region (2000-0400 MLT) sharply in summer and more gradually in winter. In general, the duration of the trough was shorter during summer than that during winter or equinox because of longer exposure to sunlight. In addition, the seasonal variations in trough minimum position differed strongly with different MLT values.

Figure 10 illustrates the MLT variation of trough depth (left panel), background TEC (middle panel), and TEC value at the trough minimum (right panel) in the same manner as Fig. 9. The results show that the trough depth tended to decrease with MLT in the dusk-side (18002200 MLT) and morning (0300-0600 MLT) regions, while it increased with MLT in the midnight region (2200-0300 MLT). In the dusk-side region, both the background TEC and the TEC value at the trough minimum decreased with time, but the variation in the background TEC was larger than the variation in the trough minimum TEC, which means the TEC value inside the trough decreases more slowly with MLT than the TEC value outside this region. In the midnight region, the background TEC remained unchanged during summer or equinox, whereas the TEC value at the trough minimum decreased with MLT, which indicates that some mechanisms (e.g., the chemical loss process (Lee et al. 2011)) continue to deplete plasma density in the trough during this period. However, in winter, the background TEC increased with MLT in the midnight region, and the TEC value at the trough minimum changed little with MLT. Rodger (2008) suggested that perhaps several mechanisms that deplete plasma density in the trough may be occurring at the same time, but their relative importance probably changes between events. It is reasonable to suppose that the equatorward wind makes a greater contribution to TEC values in winter. The midlatitude meridional winds are equatorward through the night and generally peak around 0100-0200 LT (Emmert et al. 2002; Fisher et al. 2015). During winter, the equatorward neutral winds have a more dominant effect in increasing the ionization with MLT than the ordinary ionic recombination in lowering the ionization because of the lower TEC value. A quantitative test of the wind effect in the trough is needed in the future. In the morning region, the trough depth is primarily associated with the scattered solar extreme ultraviolet (EUV) radiation (Schunk et al. 1976).

Finally, the variations of the trough minimum position estimated by the IRI-2007 model were compared with the variations of the GPS-TEC trough minimum position with respect to MLT and F107. The results are 

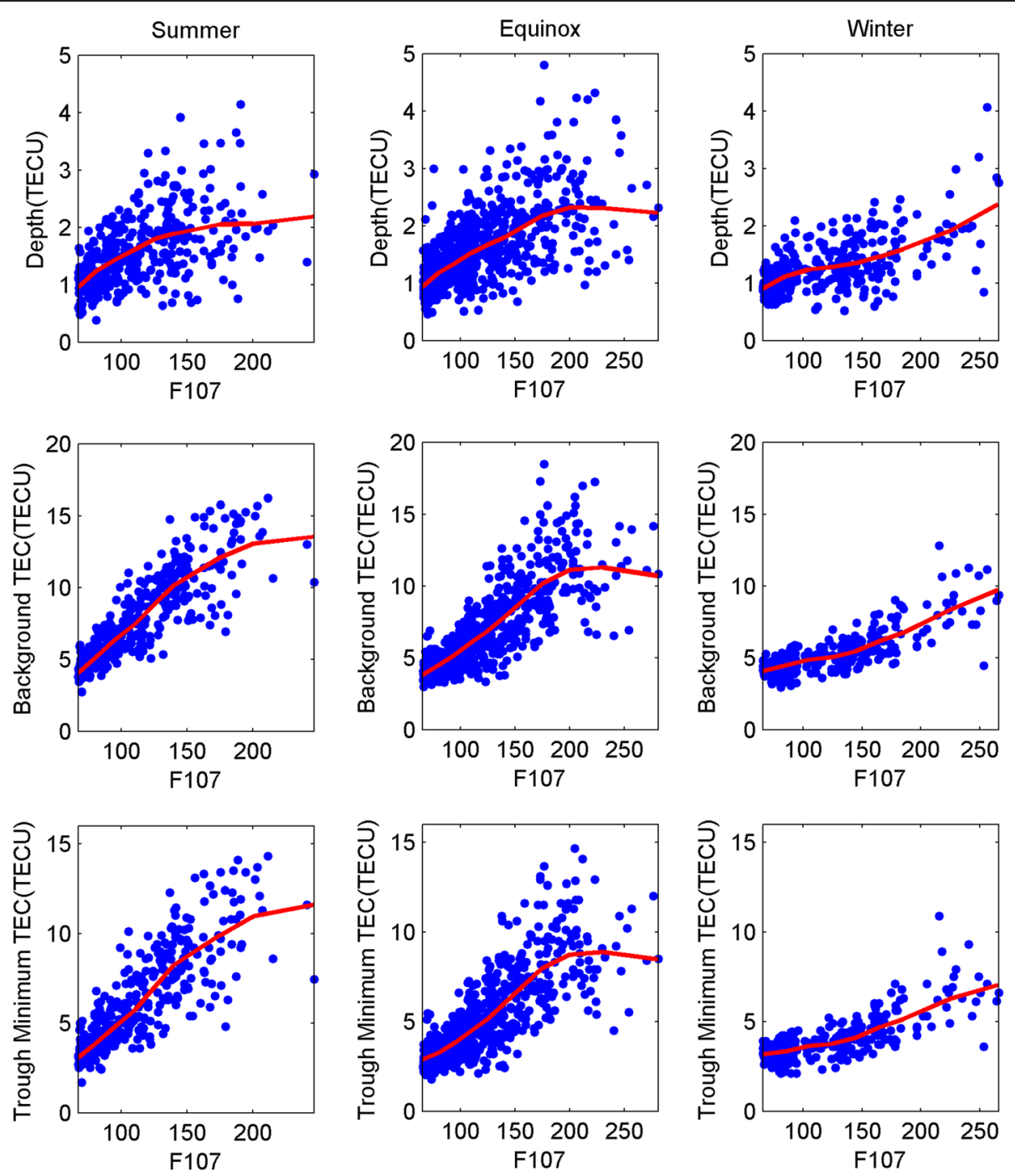

Fig. 7 The solar activity variation in the trough depth (upper panels), background TEC (middle panels), and TEC value at the trough minimum (lower panels) under a low $(1.5 \leq \mathrm{Kp} \leq 2.5)$ geomagnetic activity condition. The left, middle, and right panels show the results for the summer, equinox, and winter seasons, respectively. The red solid lines represent the piecewise fitting results
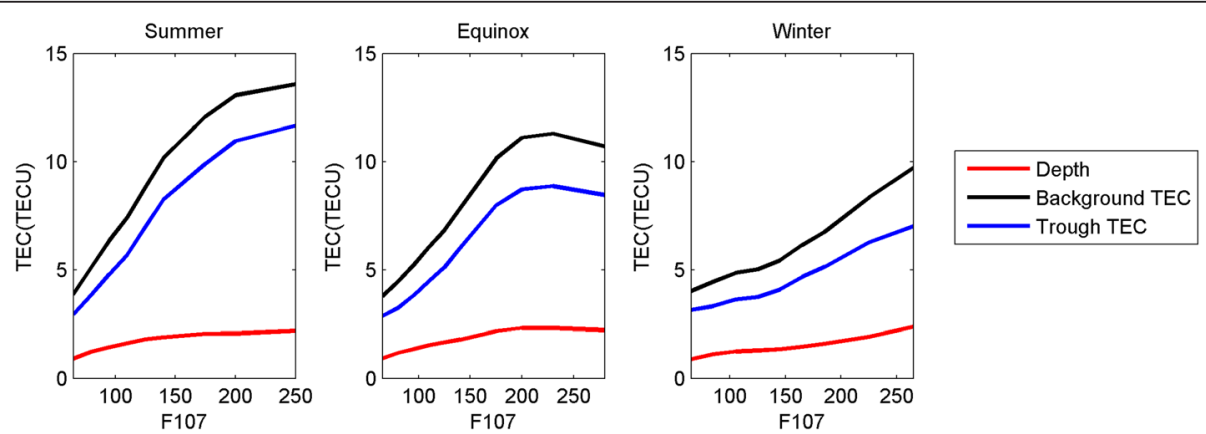

Fig. 8 The piecewise fitting curves derived from Fig. 7 are shown. The left, middle, and right panels show the results for the summer, equinox, and winter seasons, respectively. The red lines denote the variation in the trough depth with respect to F107. The black lines denote the variation in the background TEC. The blue lines denote the variation in the TEC value of the trough minimum 


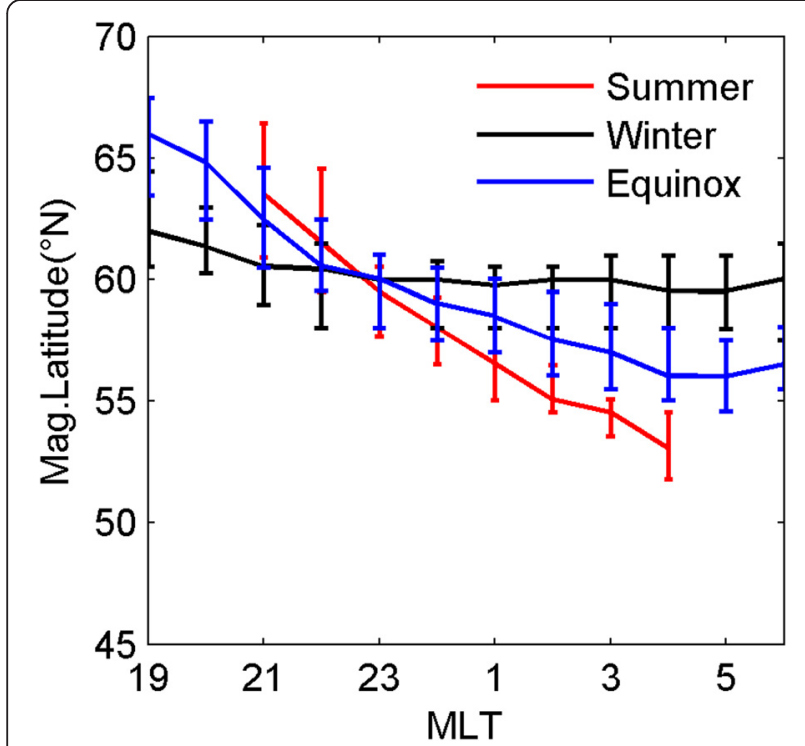

Fig. 9 The MLT variation of the trough minimum position during different seasons. The data correspond to the median solar activity $(90 \leq \mathrm{F} 107 \leq 150)$ and low geomagnetic activity $(0.3 \leq$ $\mathrm{Kp} \leq 2)$ conditions. The red, black, and blue lines denote the results for summer, winter, and equinox seasons, respectively. The median and the upper and lower quartiles of these parameters are shown for each $1 \mathrm{~h}$ interval of MLT

shown in Fig. 11. The IRI-TEC trough minimum position is produced by the longitudinal average of the trough minimum positions over 13 longitudes $(-180,-150,-120,-90,-60,-30,0,30,60,90,120$, $150,180)$ at the local time. The left and right columns show the results for the IRI-TEC trough and the GPS-TEC trough, respectively. The upper panels show the variation of the trough minimum position with respect to MLT in different seasons at a low geomagnetic activity level. The diurnal variation in the IRI-TEC trough was similar to that of the GPSTEC trough. However, the IRI-TEC trough was located at higher latitudes. The lower panels show the variation of the midnight trough minimum position with respect to F107 in winter. The GPS-TEC trough minimum position changed little with F107, whereas the IRI-TEC trough minimum position showed a strong F107 dependence. The IRI-TEC did not show any response to geomagnetic activity. However, the trough minimum position depends primarily on geomagnetic activity. The F107 dependence of the IRITEC trough minimum position may be affected by the variation of geomagnetic activity. Therefore, the model needs to be further corrected according to geomagnetic activity.

\section{Conclusions}

This study statistically analyzed the geomagnetic, solar activity, seasonal, and MLT variations of trough parameters (trough minimum position, trough depth, and trough width and half-width) by using GPS-TEC data collected during 2000-2014. The results were compared with the variations of the IRI-TEC trough. The results are summarized as follows:

1. The trough minimum position depends primarily on geomagnetic activity, MLT, and the season. The trough shifts toward low latitudes with increasing geomagnetic activity and MLT. The seasonal variation in trough minimum position differs strongly with different MLTs.

2. The trough depth depends primarily on F107 and, to a lesser degree, on MLT. The trough depth increases with increasing F107 and with decreasing incidence angle of solar flux.

3. The trough equatorward half-width decreases with increasing geomagnetic activity.

4. The diurnal variation in the IRI-TEC trough minimum position is similar to that of the GPSTEC trough minimum position. The GPS-TEC
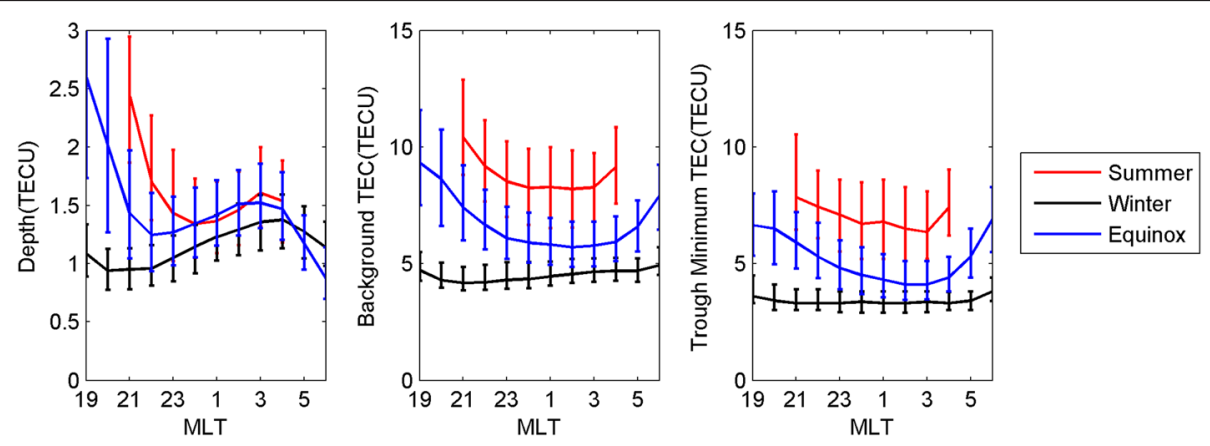

Fig. 10 The MLT variation of the trough depth (left panel), background TEC (middle panel), and TEC value at the trough minimum (right panel) during different seasons. The red, black, and blue lines denote the results for summer, winter, and equinox seasons, respectively. The median and the upper and lower quartiles of these parameters are shown for each $1 \mathrm{~h}$ interval of MLT 

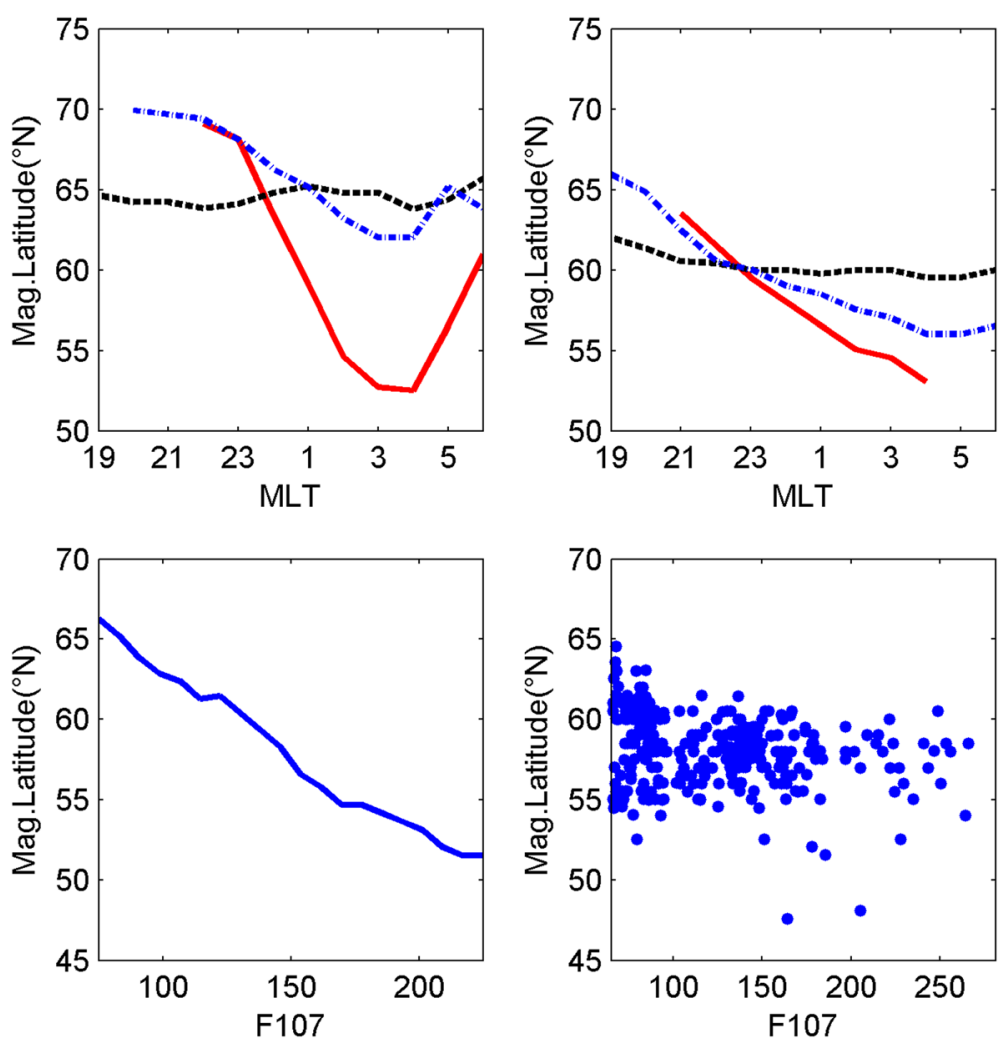

Fig. 11 A comparison of trough positions derived from GPS-TEC (right panels) with TEC trough positions generated by the IRI model (left panels), as a function of MLT (upper panels), and as a function of F107 in winter (lower panels). The red, black, and blue lines in the upper panels denote the results for the summer, winter, and equinox seasons, respectively

trough minimum position changes little with F107, whereas the IRI-TEC trough minimum position shows a strong F107 dependence.

In this study, we examined the trough structure averaged longitudinally over the course of a day. The longitudinal average of the trough structure depends not only on the longitude effect of the trough occurrence rate (He et al. 2011) but also on the longitude effect of the trough structure (Karpachev 2003). The occurrence rate of the trough shows significant variations depending on the season, solar activity, and MLT (Ishida et al. 2014). The longitude effect of the trough minimum position primarily depends on the Kp (Karpachev et al. 1996). These factors can lead to the large scatter of the data and make the interpretation of the data in terms of physical processes more difficult. Although these limitations exist, our results are consistent with those found in many earlier studies. During disturbed conditions, the temperature associated with the disturbed electric field increases in the trough region, and the plasma density at a trough minimum decreases. However, in this study, the TEC at the trough minimum remained constant with increasing Kp. Pryse et al. (2006) investigated the TEC trough in the United Kingdom and found the same feature. Therefore, the relationship between the TEC value at the trough minimum and the temperature at the trough minimum is needed to study at different geomagnetic activities, which can help us understand the physical mechanism of trough formation. In addition, a quantitative test of the wind effect in the trough is also needed in the future.

The mid-latitude trough is a typical feature of the $\mathrm{F}$ region. It has been demonstrated that GPS-TEC data can be used to investigate the time and space evolution of the trough, although the data provide no altitudinal information.

\section{Competing interests}

The authors declare that they have no competing interests.

\section{Authors' contributions}

NY and HL planned and led the study, interpreted the results, and drafted the manuscript. LL participated in the data analysis and interpretation. All authors read and approved the final manuscript.

\section{Acknowledgements}

This research was supported by the Chinese Academy of Sciences project (KZZD-EW-01-3), National Key Basic Research Program of China (2012CB825604), and National Natural Science Foundation of China (41374162, 41231065, and 41321003). The GPS-TEC data used in this study 
were downloaded from MIT Haystack's Madrigal database mirror site at the Institute of Geology and Geophysics, Chinese Academy Sciences (http://madrigal.iggcas.ac.cn/madrigal/).

\section{Author details}

${ }^{1}$ Key Laboratory of Earth and Planetary Physics, Institute of Geology and Geophysics, Chinese Academy of Sciences, Beijing, China. ${ }^{2}$ Beijing Nationa Observatory of Space Environment, Institute of Geology and Geophysics, Chinese Academy of Sciences, Beijing, China. ${ }^{3}$ University of the Chinese Academy of Sciences, Beijing 100049, China.

Received: 20 August 2015 Accepted: 27 November 2015

Published online: 08 December 2015

\section{References}

Balan N, Bailey GJ, Su YZ (1996) Variations of the ionosphere and related solar fluxes during solar cycles 21 and 22. Adv Space Res 18(3):11-14

Collis PN, Häggström I (1988) Plasma convection and auroral precipitation processes associated with the main ionospheric trough at high latitudes. J Atmos Terr Phys 50:389-404

Doe RF, Vickrey JF, Mendillo M (1995) Electrodynamic model for the formation of auroral ionospheric cavities. J Geophys Res 100:9683-9696. doi:10.1029/95JA00001

Emmert JT, Fejer BG, Shepherd GG, Solheim BH (2002) Altitude dependence of middle and low-latitude daytime thermospheric disturbance winds measured by WINDII. J Geophys Res 107(A12):1483. doi:10.1029/2002JA009646

Evans JV, Holt JM, Oliver WL, Wand RH (1983) The fossil theory of nighttime high latitude F region troughs. J Geophys Res 88(A10):7769-7782

Fisher DJ, Makela JJ, Meriwether JW, Buriti RA, Benkhaldoun Z, Kaab M, Lagheryeb A (2015) Climatologies of nighttime thermospheric winds and temperatures from Fabry-Perot interferometer measurements: from solar minimum to solar maximum. J Geophys Res Space Physics 120:6679-6693. doi:10.1002/2015JA021170

He M, Liu L, Wan W, Zhao B (2011) A study on the nighttime midlatitude ionospheric trough. J Geophys Res 116:A05315. doi:10.1029/2010JA016252

Hedin M, Häggström I, Pellinen-Wannberg A, Andersson L, Brändström U, Gustavsson B, Steen Å, Westman A, Wannberg G, Van Eyken T, Aso T, Cattell C, Carlson CW, Klumpar D (2000) 3-D extent of the main ionospheric trough — a case study. Adv Pol Up Atm Res 14:157-162

Horvath I, Essex EA (2003) The Southern Hemisphere mid-latitude day-time and nighttime trough at low-sunspot numbers. J Atmos Terr Phys 65:917-940

Ishida T, Ogawa Y, Kadokura A, Hiraki Y, Häggström I (2014) Seasonal variation and solar activity dependence of the quiet-time ionospheric trough. J Geophys Res Space Physics 119. doi:10.1002/2014JA019996.

Karpachev AT (2003) The dependence of the main ionospheric trough shape on longitude, altitude, season, local time, and solar and magnetic activity. Geomagn Aeron 43(2):239-251

Karpachev AT, Deminov MG, Afonin W (1996) Model of the mid-latitude ionospheric trough on the base of cosmos-900 and intercosmos-19 satellites data. Adv Space Res 18:6221-6230

Knudsen WC (1974) Magnetospheric convection and the high-latitude F2 ionosphere. J Geophys Res 79(7):1046-1055

Krankowski A, Shagimuratov II, Ephishov II, Krypiak-Gregorczyk A, Yakimova G (2008) The occurrence of the mid-latitude ionospheric trough in GPS-TEC measurements. Adv Space Res 43:1721-1731. doi:10.1016/j.asr.2008.05.014

Lee I, Liu JY, Wang W, Chen C, Lin C (2011) The ionospheric mid-latitude trough observed by FORMOSAT-3/COSMIC during solar minimum. J Geophys Res 116:A06311. doi:10.1029/2010JA015544

Liu JY, Chen Yl, Lin JS (2003) Statistical investigation of the saturation effect in the ionospheric foF2 versus sunspot, solar radio noise, and solar EUV radiation. J Geophys Res 108(A2):1067. doi:10.1029/2001JA007543

Liu L, Wan W, Ning B, Pirog OM, Kurkin VI (2006) Solar activity variations of the ionospheric peak electron density. J Geophys Res 111:A08304. doi:10.1029/2006JA011598

Lyatsky VB, Mal'tsev P (1981) Origin of the mid-latitude trough and of the polar void in the ionospheric density distribution. Geomag Aeronomy 21:127-128

Mendillo M, Chacko CC (1977) The baselive ionospheric trough. J Geophys Res 82:5129-5137

Middleton HR, Pryse SE, Wood AG, Balthazor R (2008) The role of the tongue-of-ionization in the formation of the poleward wall of the main trough in the European post-midnight sector. J Geophys Res 113: A02306. doi:10.1029/2007JA012631

Muldrew DB (1965) F-layer ionization troughs deduced from Alouette data. J Geophys Res 70(11):2635-2650

Nilsson H, Sergienko TI, Ebihara Y, Yamauchi M (2005) Quiet-time mid-latitude trough: influence of convection field-aligned currents and proton precipitation. Ann Geophys 23:3277-3288

Ohtani S, Wing S, Merkin VG, Higuchi T (2014) Solar cycle dependence of nightside field-aligned currents: effects of dayside ionospheric conductivity on the solar wind-magnetosphere-ionosphere coupling. J Geophys Res Space Physics 119:1-13. doi:10.1002/2013JA019410

Pryse SE, Kersley L, Malan D, Bishop GJ (2006) Parameterization of the main ionospheric trough in the European sector. Radio Sci 41:RS5S14. doi:10.1029/2005RS003364

Rideout W, Coster A (2006) Automated GPS processing for global total electron content data. GPS Solut 10(3):219-228. doi:10.1007/s10291-006-0029-5

Rodger A (2008) The mid-latitude trough: revisited, in mid-latitude ionospheric dynamics and disturbances. Geophys Monogr Ser 181:25-33, AGU Washington D.C

Rodger AS, Brace LH, Hoegy WR, Winningham JD (1986) The poleward edge of the mid-latitude trough-its formation, orientation and dynamics. J Atmos Sol Terr Phys 48(8):715-728

Rodger AS, Moffett RJ, Quegan S (1992) The role of ion drift in the formation of ionisation troughs in the mid-and high-latitude ionosphere-a review. J Atmos Sol Terr Phys 54(1):1-30

Schunk RW, Banks PM, Raitt WJ (1976) Effects of electric fields and other processes upon the nighttime high latitude F layer. J Geophys Res 81:3271

Spiro RW, Heelis RA, Hanson WB (1978) Ion convection and the formation of the mid-latitude F region ionization trough. J Geophys Res 83(A9):4255-4264. doi:10.1029/JA083iA09p04255

Wielgosz P, Baran LW, Shagimuratov II, Aleshnikova MV (2004) Latitudinal variations of TEC over Europe obtained from GPS observations. Ann Geophys 22:405-415. doi:10.5194/angeo-22-405-2004

Zou S, Moldwin MB, Coster A, Lyons LR, Nicolls MJ (2011) GPS TEC observations of dynamics of the mid-latitude trough during substorms. Geophys Res Lett 38:L14109. doi:10.1029/2011GL048178

\section{Submit your manuscript to a SpringerOpen ${ }^{\odot}$ journal and benefit from:}

- Convenient online submission

- Rigorous peer review

- Immediate publication on acceptance

- Open access: articles freely available online

- High visibility within the field

- Retaining the copyright to your article

Submit your next manuscript at springeropen.com 